\title{
Preparation of polyacrylate/silica membranes for fuel cell application by in situ UV polymerization
}

\author{
Mariia Zhyhailo', \\ Iryna Yevchuk ${ }^{1}$, \\ Mykhaylo Yatsyshyn², \\ Sergiy Korniy ${ }^{3}$,
}

Oksana Demchyna ${ }^{1}$,

Rostyslav Musiy ${ }^{1}$,

Rimantas Raudonis ${ }^{4}$,

\author{
Aleksej Zarkov ${ }^{4}$ \\ $\operatorname{Aivaras~Kareiva~}^{4^{*}}$ \\ ${ }^{1}$ Department of Physical Chemistry \\ of Fuel Fossils L. M. Lytvynenko Institute \\ of Physico-organic Chemistry \\ and Coal Chemistry NAS of Ukraine, \\ 3 a Naukova Street, \\ 79060 Lviv, Ukraine \\ ${ }^{2}$ Ivan Franko National University of Lviv, \\ 6 Kyryla \& Mefodiya Street, \\ 79005 Lviv, Ukraine \\ ${ }^{3}$ Karpenko Physical-Mechanical Institute \\ NAS of Ukraine, \\ 5 Naukova Street, \\ 79060 Lviv, Ukraine \\ ${ }^{4}$ Institute of Chemistry, \\ Faculty of Chemistry and Geosciences, \\ Vilnius University, \\ 24 Naugarduko Street, \\ 03225 Vilnius, Lithuania
}

The development of proton conductive polyacrylate membranes based on acrylonitrile, sodium 4-vinylbenzenesulfonate, acrylic acid, ethylene glycol dimethacrylate and hybrid polyacrylate/silica membranes is reported in this article. Polyacrylate membranes were synthesized via UV-initiated copolymerization; for the synthesis of polyacrylate/silica membranes 3-methacryloxypropyl trimethoxysilane-based sol-gel system was introduced into the polymerizing mixture.

Keywords: organic-inorganic material, proton conductive membrane, sol-gel precursor, acrylic monomer, 3-methacryloxypropyl trimethoxysilane

\footnotetext{
* Corresponding author: Email: aivaras.kareiva@chgf.vu.lt
} 


\section{INTRODUCTION}

The energy sector of the economy is constantly expanding. A recent report of Cleantech Group emphasized that hydrogen technology will become one of the most important industries in the coming decade [1]. This technology is considered as a great opportunity to reduce emissions and increase the value of 'clean' energy. Hydrogen fuel cells may be used for heating and electrification of buildings, as an alternative fuel for cars and trains, etc. [2-4]. Therefore, the efforts of the researchers all over the world are directed to acceleration of the deployment of fuel cell technology.

One of the challenges in this research field is the development of the effective proton conductive membranes being really 'the heart' of the fuel cell. A large variety of materials for proton conductive membranes are currently being developed and tested. The hybrid organic-inorganic material approach has been successfully developed, since these materials combine the intrinsic physical and chemical properties of both the organic and inorganic components.

Sol-gel technique widely reported recently allows a fine tuning of the inorganic network, so hybrid membranes are a promising family for controlling conductivity, mechanical and chemical properties of proton conductive membranes and some alternative to commercial Nafion-type membranes [5]. Sol-gel technique involves the low temperature hydrolysis and condensation of precursors - alkoxides or organically modified alkoxides. When the sol-gel process occurs in situ in an organic matrix, new hybrid organic-inorganic networks are formed. Different precursors are currently being explored to provide high performance of proton conductive membranes. The authors [6] have synthesized methacrylate-silica covalent hybrid membranes by polymerization of 2-hydroxyethyl methacrylate and 3-methacryloxypropyl trimethoxysilane, and hydrolysis-polycondensation of alkoxide radicals. Tungstophosphoric acid hydrate was incorporated to endow the membranes with proton conductivity. The water retention properties provided by $\mathrm{SiO}_{2}$ and tungstophosphoric acid lead to high proton conductivity (up to $3 \times 10^{-2} \mathrm{~S} / \mathrm{cm}$ at $100-150^{\circ} \mathrm{C}$ ).

In 肺 anion-exchange organic-inorganic hybrid membranes were prepared through the sol- gel reaction and UV/thermal curing of positively charged alkoxysilane and alkoxysilane containing acrylate or epoxy groups. Methacryloxypropyl trimethoxysilane, glycidoxypropyl trimethoxysilane, triethoxysilylpropylamine and tetraethoxysilane were used as sol-gel precursors. Properties of the synthesized membranes were varied by the control of the precursor molar ratio. In the solgel process hydrolysis and polycondensation of $\left(-\mathrm{Si}(\mathrm{OR})_{3}\right)$ groups take place. During the subsequent UV- or thermally-curing steps acrylate and epoxy groups undergo cross-linking reactions forming an organic polymeric network. The obtained hybrid organic-inorganic membranes were found to have high thermal stability, water uptake and ion exchange capacity (IEC) values and can be used for fuel cell application.

A new class of proton-electrolyte membranes based on organic-inorganic copolymers were synthesized by S. Li and co-authors [8] from 3-glycidoxypropyl trimethoxysilane (GPTMS), sulfonated phenyltriethoxysilane (SPS), tetraethoxysilane (TEOS) and $\mathrm{H}_{3} \mathrm{PO}_{4}$. Their thermal stability and proton conductivity were investigated under the conditions for PEM fuel cell operation. In an environment with $15 \%$ relative humidity the proton conductivity increased to $3.6 \times 10^{-2} \mathrm{~S} / \mathrm{cm}$ at $120^{\circ} \mathrm{C}$. These hybrid materials can be readily fabricated in $20 \mu \mathrm{m}$ thick membranes.

Several studies have reported that introduction of silica derived from 3-mercaptopropyl trimethoxysilane (MPTMS) to organic matrix generates homogeneous nanocomposite membranes with good proton conductivity and greatly decreased methanol permeability [9-10]. J. Mosa and coworkers [9] have used MPTMS and GPTMS as sol-gel precursors for the synthesis of sulfonic acid-functionalized hybrid organic-inorganic PEM. The membranes were prepared by sol-gel method and organic polymerization of GPTMS. All obtained membranes were chemically and thermally resistant and demonstrated proton conductivities as high as $0.16 \mathrm{~S} / \mathrm{cm}$ at temperatures higher than $100^{\circ} \mathrm{C}$ while exhibiting a low methanol permeability.

Sh. An and co-workers [11] reported the synthesis of a series of pure and organic-inorganic cross-linked membranes on the basis of 2-acrylamido-2-methylpropane sulfonic acid (AMPS) accompanied with cross-linkers and sol-gel precursors, 3-methacryloxypropyl trimethoxysilane 
(KH570) and TEOS, introduced into the organic membrane matrices via free-radical polymerization, which took place under UV-irradiation. The prepared membrane showed a high IEC, a large ion flux, as well as an excellent thermal and mechanical stability.

Hence, the incorporation of silica by sol-gel transformation of precursors into organic matrices having proton conductivity allows obtaining of membranes with enhanced physicochemical stability and performance.

The present study was carried out in order to synthesize cross-linked organic-inorganic membranes for fuel cells using acrylic monomers and the sol-gel system based on 3-methacryloxypropyl trimethoxysilane and tetraethyl orthosilicate by photochemical means. The possibility of tuning of polyacrylate/silica membrane properties by changing of the organic matrix/sol-gel precursor ratio was shown.

\section{EXPERIMENTAL}

\section{Materials}

Sodium 4-vinylbenzenesulfonate (NaSS), acrylonitrile (AN), acrylic acid (AA), 3-methacryloxypropyl trimethoxysilane (MAPTMS), tetraethyl orthosilicate (TEOS), ethylene glycol dimethacrylate (EGDMA), photoinitiator 2,2-dimethoxy-1,2diphenyl-ethane-1-on (PI), hydrogen peroxide $\left(\mathrm{H}_{2} \mathrm{O}_{2}\right)(30 \% \mathrm{w} / \mathrm{v})$ and hydrochloric acid $(\mathrm{HCl})$ (35\%) were purchased from Sigma-Aldrich. Absolute ethanol was used as a solvent and phosphoric acid (85\%) as a catalyst of sol-gel reaction. All chemicals were used as received.

\section{Preparation of sol-gel system}

The sol-gel precursor solution was prepared by mixing of MAPTMS, TEOS, ethanol, water and phosphoric acid with a respective ratio of $0.25: 0.75: 4: 4: 1.2 \mathrm{~mol} / \mathrm{mol}$ and continuously stirred at $500 \mathrm{rpm}$ in a $50 \mathrm{C}$ water bath for 180 $200 \mathrm{~min}[12]$.

\section{Synthesis of membranes}

The aqueous monomer solution was prepared by dissolving of water-soluble reagents (NaSS, EGDMA and AA). Then the solution was mixed with the appropriate amount of AN containing PI under constant stirring at $500 \mathrm{rpm}$ for
30 min. The mixture was cast to glass mould $(50 \times 20 \times 0.15 \mathrm{~mm})$ and exposed to UV light $(365 \mathrm{~nm})$ for $20 \mathrm{~min}$. To prevent the inhibiting effect of oxygen on polymerization process the moulds were covered with a glass slide.

After UV exposure, the obtained membranes with an average thickness of 100-150 $\mu \mathrm{m}$ were washed with a large excess of water to remove unreacted compounds. Finally, the membrane samples were dried in an oven at $50^{\circ} \mathrm{C}$ until constant weight [13, 14]. For obtaining organic-inorganic membranes the appropriate amount of sol-gel precursor solution was added to the monomer mixture before polymerization.

The ratio between components in feed compositions for the membrane preparation is presented in Table 1. To initiate polymerization, $2.0 \mathrm{wt} . \%$ of PI was added to the compositions. Figure 1 shows the scheme of the synthesis of polymeric matrix of the membrane.

\section{Membrane characterization}

FTIR spectra of the membranes were recorded using a spectrometer Nicolet IS 10 ATR with a resolution of $10 \mathrm{~cm}^{-1}$ in a spectral range of 4000 $600 \mathrm{~cm}^{-1}$. The morphology of polymer-inorganic membranes was investigated using a ZEISS EVO 40XVP scanning electron microscope. Elemental microanalysis was determined by an energy dispersive X-ray spectrometer INCA Energy 350. Thermogravimetric-differential thermal analysis (TG-DTA) was performed using a Derivatograph Q-1500D (Paulik-Paulik-Erdey) within a temperature range of $20-400^{\circ} \mathrm{C}$ with a heating rate of $5{ }^{\circ} \mathrm{C} / \mathrm{min}$.

The resistance of polymeric and polymer-inorganic membranes was measured by impedance spectroscopy using an AUTOLAB impedance spectrometer (EcoChem) with the FRA software.

Table 1. Feed compositions for membrane preparation

\begin{tabular}{c|c|c|c|c|c}
\hline Sample & $\begin{array}{c}\text { AN, } \\
\text { wt.\% }\end{array}$ & $\begin{array}{c}\text { AA, } \\
\text { wt.\% }\end{array}$ & $\begin{array}{c}\text { NaSS, } \\
\text { wt.\% }\end{array}$ & $\begin{array}{c}\text { EGDMA, } \\
\text { wt. }\end{array}$ & $\begin{array}{c}\text { SGS, } \\
\text { wt.\% }\end{array}$ \\
\hline S1 & 44.0 & 20.0 & 14.0 & 20.0 & - \\
\hline S2 & 42.7 & 19.4 & 13.5 & 19.4 & 3.0 \\
\hline S3 & 41.8 & 19.0 & 13.2 & 19.0 & 5.0 \\
\hline S4 & 40.8 & 18.6 & 13.0 & 18.6 & 7.0 \\
\hline S5 & 39.5 & 18.0 & 12.5 & 18.0 & 10.0 \\
\hline
\end{tabular}




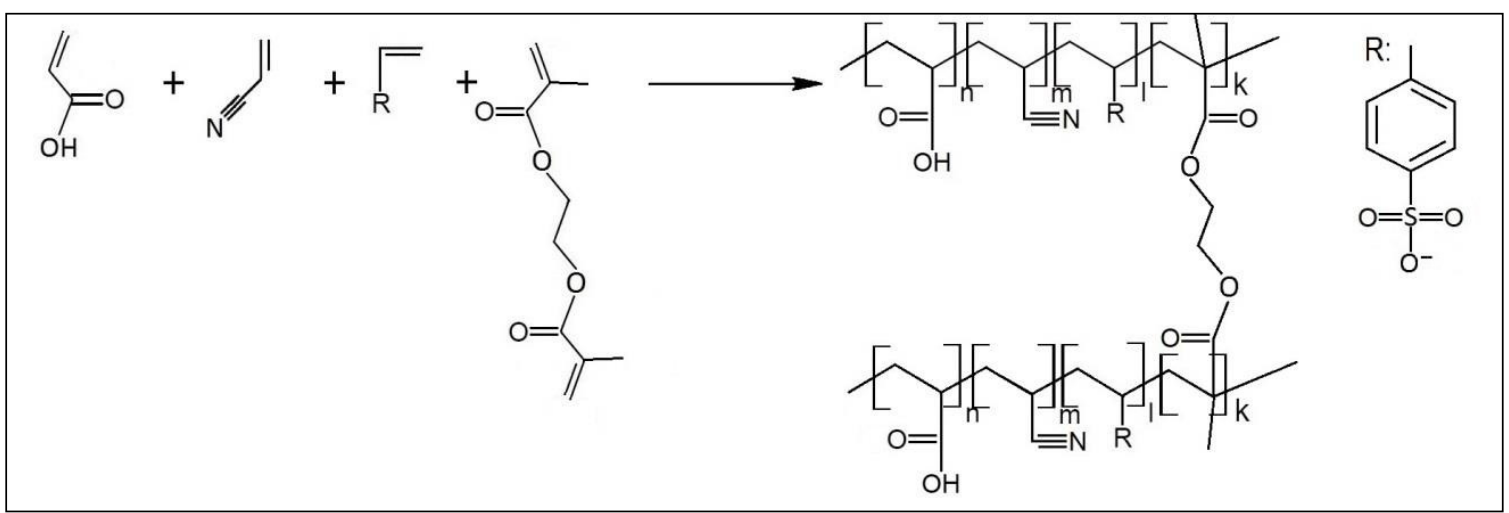

Fig. 1. Scheme of polyacrylate matrix synthesis

During the measurement, a membrane sample was sandwiched between Pt electrodes, which were then placed inside an oven with the controlled temperature and humidity: Nyquist curves for all the samples were plotted over a frequency range of $10-10^{5} \mathrm{~Hz}$. Before the measurement, all samples were converted to an acid form by immersing them in $0.1 \mathrm{M} \mathrm{HCl}$ at room temperature for $12 \mathrm{~h}$. The proton conductivity $\sigma(\mathrm{S})$ of the membrane was calculated by Eq. (1)

$$
\sigma=\frac{L}{R S}
$$

where $L$ is the sample thickness, $\mathrm{cm}$; $R$ is the membrane resistance, Ohm; $S$ is the electrode-electrolyte contact area, $\mathrm{cm}^{2}$. The reported value was the mean of three measurements.

Sorption properties of the composite membranes were determined by measuring of the mass difference before and after swelling in water. The samples were dried at $50^{\circ} \mathrm{C}$ till constant weight and placed into distilled water for $24 \mathrm{~h}$. Then the samples were wiped with the filter paper and immediately weighed.

Oxidative stability of the prepared membrane strips with a size of $1 \mathrm{~cm} \times 3 \mathrm{~cm}$ was examined by immersing them in Fenton's reagent (3\% aqueous solution $\mathrm{H}_{2} \mathrm{O}_{2}$ containing 2 ppm $\mathrm{FeSO}_{4}$ ) at room temperature. The degradation of membranes was evaluated by measuring of their weight.

\section{RESULTS AND DISCUSSION}

The synthesis of membranes occurs via photoinitiated free radical copolymerization of a monomer mixture under UV irradiation with a simultaneous sol-gel process of the added sol-gel system based on MAPTMS and TEOS taking place in situ (Fig.2).
The formation of a hybrid organic-inorganic structure involves intermolecular interactions, such as hydrogen bonding, electrostatic interactions and Van der Waals forces.

Figure 3 shows the FTIR spectra of prepared polymer and polymer-inorganic membranes in a range of $4000-600 \mathrm{~cm}^{-1}$, which determine their composition. The absorption band at $2242 \mathrm{~cm}^{-1}$ may be attributed to $\mathrm{C} \equiv \mathrm{N}$ stretching vibrations [15]. The peak at $762 \mathrm{~cm}^{-1}$ corresponds to S-O stretching vibration and the peaks found at 1169, 1037 and $1009 \mathrm{~cm}^{-1}$ correspond to $\mathrm{S}=\mathrm{O}$ asymmetric and symmetric stretching vibrations [16, 17]. The strong peak of $\mathrm{C}=\mathrm{O}$ stretching vibration and a 'shoulder' are observed at 1720 and $1618 \mathrm{~cm}^{-1}$, respectively. The broad bands at $2500-3500 \mathrm{~cm}^{-1}$ (characteristic of $\mathrm{O}-\mathrm{H}$ stretching vibration) are observed due to hydrogen bonding network formation. The wagging vibration of $\mathrm{C}-\mathrm{H}$ in 1,4-substituted benzene ring was also shown at $838 \mathrm{~cm}^{-1}$ [18]. Hence, the FTIR spectra verified that the copolymerization of AA, $\mathrm{AN}$ and NaSS was carried out successfully.

The FTIR spectra of organic-inorganic membranes (Fig. 3(a)) also reveal absorption bands which prove the presence of an inorganic component in samples S2-S5: the symmetric stretching vibrations of a siloxane ( $\mathrm{Si}-\mathrm{O}-\mathrm{Si}$ ) group appear at $766 \mathrm{~cm}^{-1}$, while the asymmetric stretching vibrations of siloxane can be observed between 1200 and $1000 \mathrm{~cm}^{-1}$ [19]. New broad absorption bands appear at $957 \mathrm{~cm}^{-1}$ (characteristic of $\mathrm{Si}-\mathrm{OH}$ stretching) in hybrid membranes, arising from the products of sol-gel reaction.

The morphology of prepared membranes was investigated by SEM (Fig. 4). The images indicate the presence of a homogeneous structure within the cross-section of the surface. EDS analysis of 


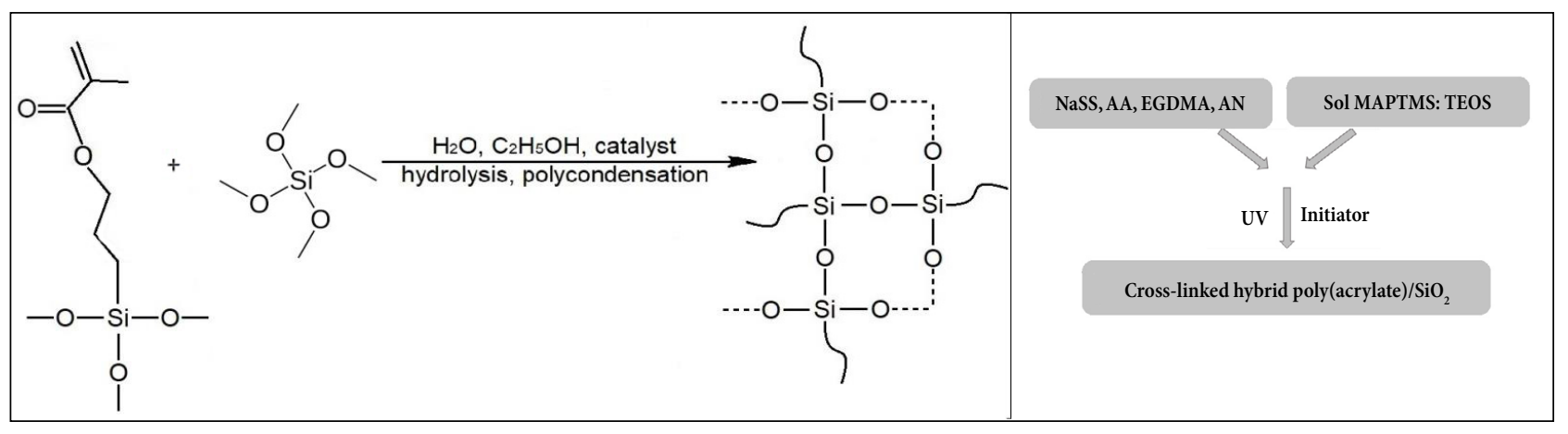

Fig. 2. Scheme of organic-inorganic membrane formation

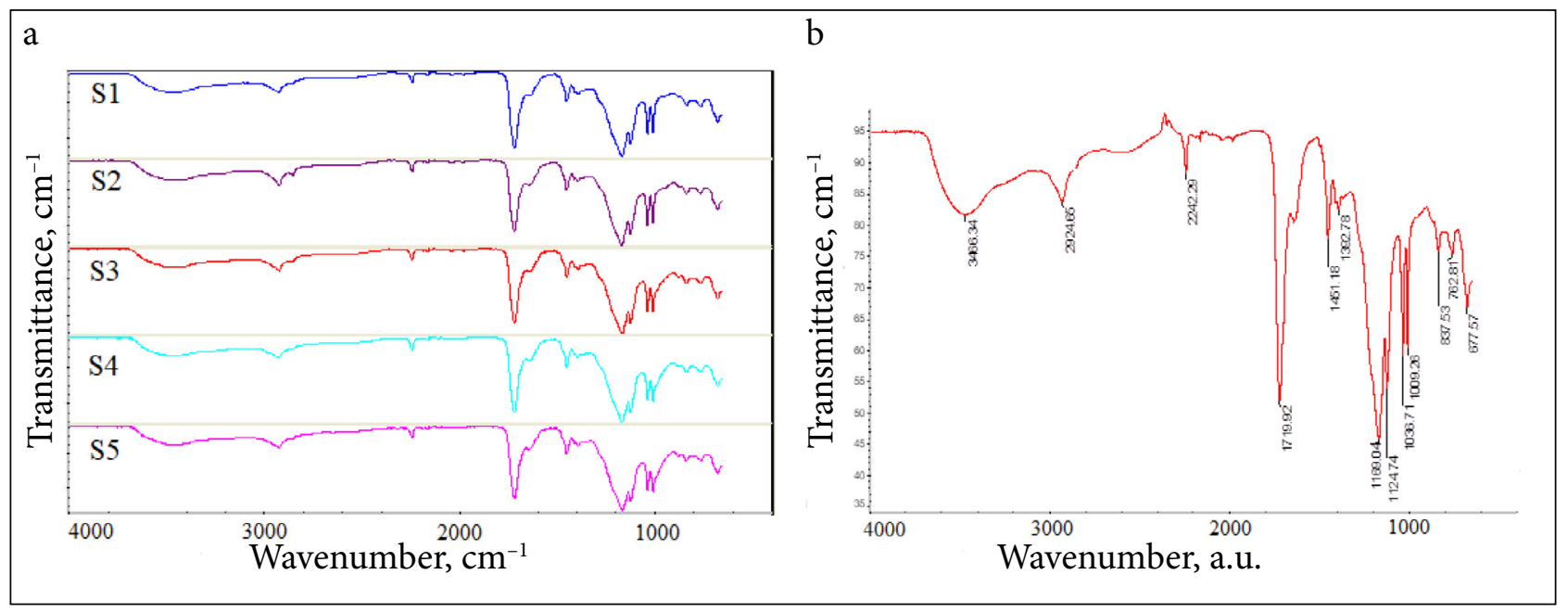

Fig. 3. FTIR spectra of membranes (a) and FTIR spectra of S1 (b) (coloured online)

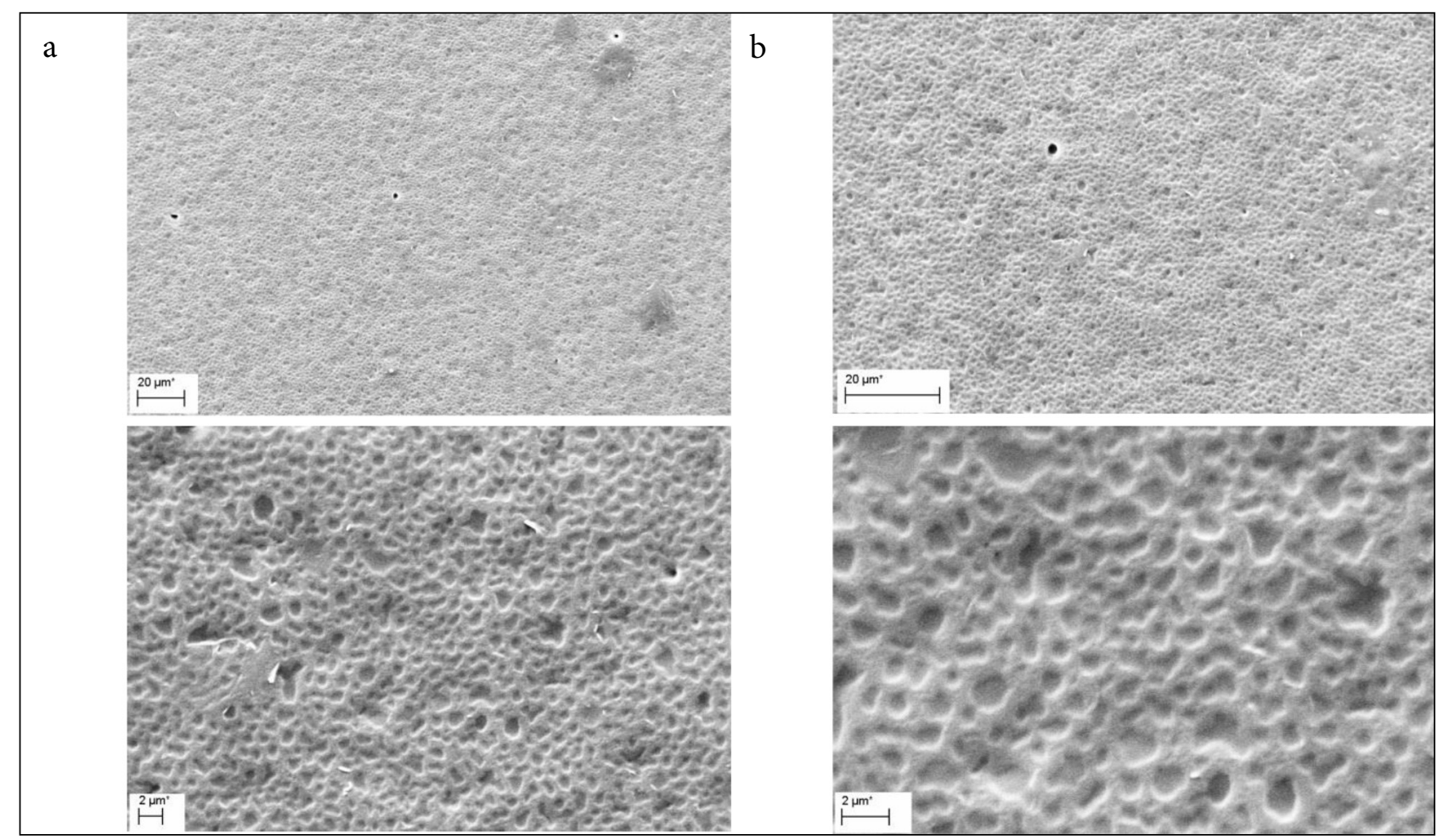

Fig. 4. Cross-sectional overview (top row) and close-view (bottom row) SEM image of polymer S1 (a) and polymer-inorganic S2 (b) membranes 


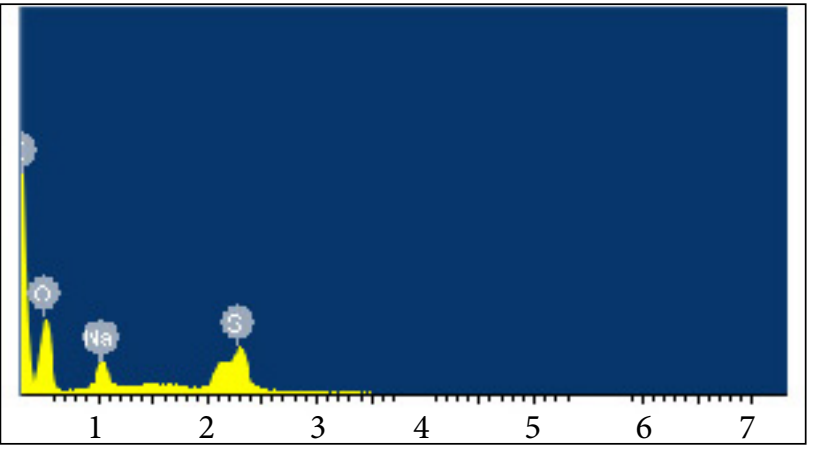

Fig. 5. ED-spectrum of the membrane S1 (coloured online) the membrane samples allows one to confirm the formation of the materials of an expected structure (Fig. 5). The intensive peak at $0.3 \mathrm{kEV}$ is assigned to $\mathrm{C}$ atoms, peaks at $0.55,1.05$ and $2.3 \mathrm{keV}$ are assigned to $\mathrm{O}, \mathrm{Na}$ and $\mathrm{S}$ atoms, respectively.

Thermogravimetric analysis was used to evaluate differences in the thermal behaviour of membranes at inorganic component variation. The results (Fig. 6) show the improvement in the thermal stability at sol-gel system addition, as can be expected. It was obvious that all the membranes

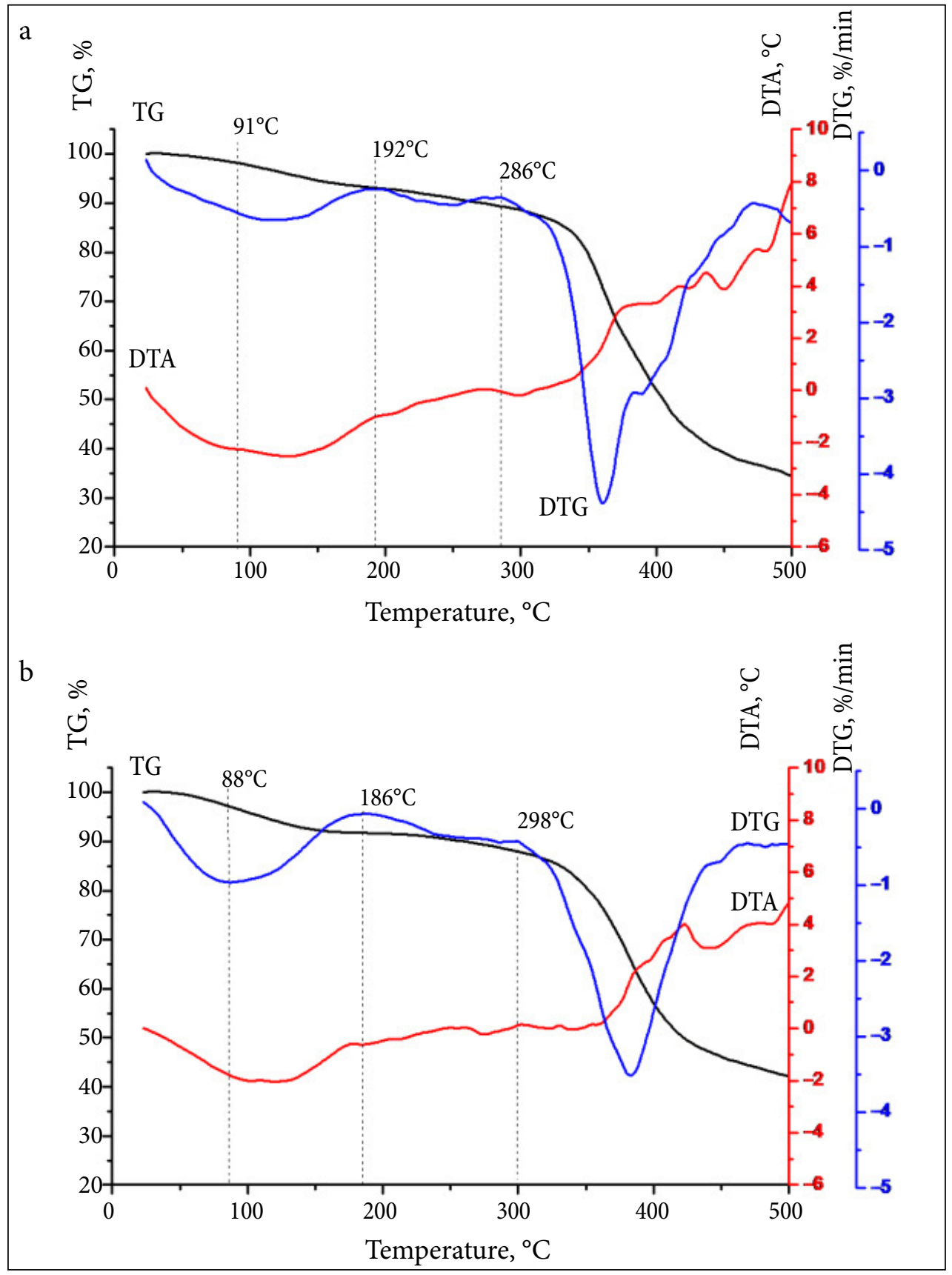

Fig. 6. TG, DTG and DTA curves for the sample S1 (a) and S5 (b) (coloured online) 
exhibited a three-step degradation curve. The first weight loss, occurring at around $30-200^{\circ} \mathrm{C}$, may be attributed to the evaporation of physically absorbed and chemically bound water. The second weight loss stage $\left(200-300^{\circ} \mathrm{C}\right)$ of polymer and polymer-inorganic membranes is attributed to the splitting-off of sulfonic acid groups. Above $350^{\circ} \mathrm{C}$, the membranes undergo the degradation step, which corresponds to the decomposition of the main polymer chain and cross-linking bridges [20].

The inspections of the thermograms suggested that polymer and organic-inorganic membranes have a good thermal stability, which can be explained as follows. First, the $\mathrm{Si}-\mathrm{O}$ bond energy is higher than that of $\mathrm{C}-\mathrm{C}$ bond. Second, the hydrolysis and condensation reactions of $\mathrm{Si}(\mathrm{OR})_{3}$ groups in the membrane lead to the formation of a crosslinked silica network structure, which makes the membrane more compact and hence improves the thermal stability [14, 21].

So, the temperature of the beginning of sulfo group decomposition for polymer membrane S1 was $286^{\circ} \mathrm{C}$, whereas that for organic-inorganic membrane S5 was $298^{\circ} \mathrm{C}$. In the processes of thermo-oxidative degradation and decomposition of sulfo groups (temperature range $286-500^{\circ} \mathrm{C}$ ), the membrane with an inorganic component loses weight less intensively (45.7 wt.\%) compared to the polymer membrane (54.6 wt.\%).

Water assists the transportation of protons from the anode to the cathode. Hence, proton conductive membranes should absorb sufficient water, whereas excessive water absorption will induce the loss of the dimensional stability and mechanical properties. Therefore, maintaining an appropriate water uptake level is crucial for proton conductive membranes.

The results of water uptake studies for membranes with a varied content of the added sol-gel system are shown in Table 2 and Fig. 8 . As one can

Table 2. Characteristics of the prepared membranes (mean \pm SD, $n=3$ )

\begin{tabular}{cc}
\hline Water uptake, wt.\% & 0xidative stability, wt.\% \\
\hline $18.07 \pm 0.26$ & $92.04 \pm 40.34$ \\
\hline $19.53 \pm 0.18$ & $92.624 \pm 40.51$ \\
\hline $20.68 \pm 0.23$ & $93.454 \pm 0.44$ \\
\hline $22.72 \pm 0.32$ & $94.24 \pm 0.56$ \\
\hline $24.15 \pm 0.22$ & $95.27 \pm 0.52$ \\
\hline
\end{tabular}

see, the water uptake of the membranes gradually increases with the increase of precursor sol content.

The proton conductivity of the synthesized membranes measured at $30^{\circ} \mathrm{C}$ was found to be dependent on the content of the inorganic component (Fig. 7). The synthesized hybrid organic-inorganic membranes demonstrate sufficiently high values of proton conductivity $-1.1710^{-3}-2.8510^{-3} \mathrm{~S} / \mathrm{cm}$.

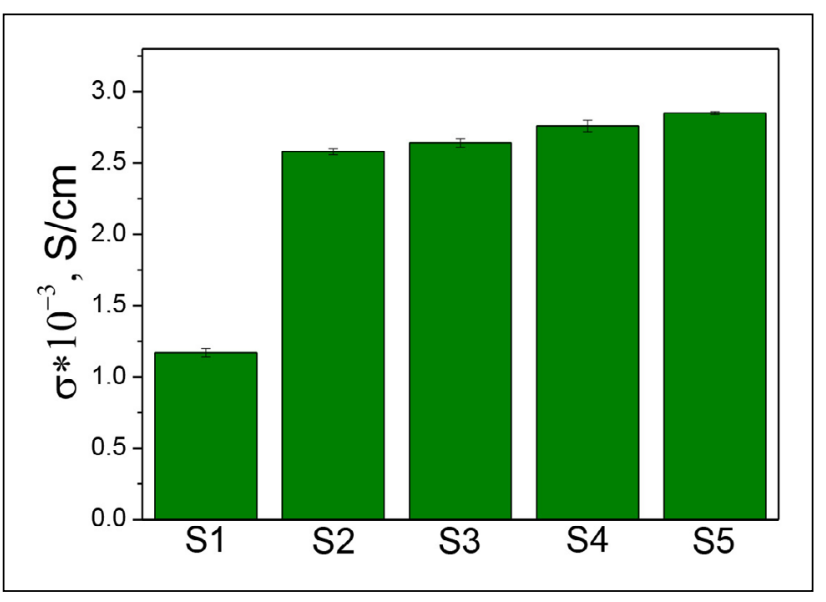

Fig. 7. Proton conductivity of membranes vs SGS content (coloured online)

The oxidative stability is an important factor that determines the life time and long-term performance of proton conductive membranes. During the operation of PEMFCs, free oxidative radicals $(\cdot \mathrm{OH}$ and $\cdot \mathrm{OOH})$ are generated as a result of $\mathrm{H}_{2} \mathrm{O}_{2}$ decomposition, the by-product due to the incomplete reduction of oxygen [18, 22]. These highly oxidative radicals attack polymer backbones and cause the membrane degradation. Fenton's reagent, which can simulate the chemical circumstances of PEMFCs in work environment, is still the most effective reagent for the oxidative stability test.

The degradation of membranes is evaluated by the weight loss and visual observation. As shown in Fig. 8, the membranes show a relatively high oxidative durability in Fenton's reagent. About 10\% weight loss was observed after membrane $\mathrm{S} 1$ was immersed in a $3 \%$ aqueous solution of $\mathrm{H}_{2} \mathrm{O}_{2}$ containing 2 ppm $\mathrm{FeSO}_{4}$ for 14 days.

Silica improves oxidative stability due to its cross-linking effect, which makes the membrane more compact. It should be noted that none of the membranes examined were broken into small pieces, all samples remained in a good shape after the test period. 


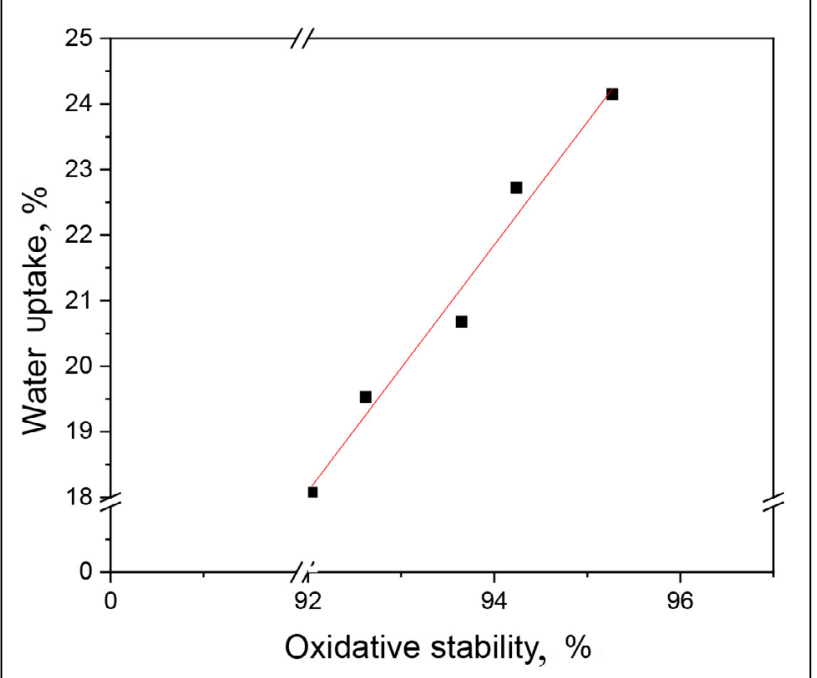

Fig. 8. Oxidative stability vs water uptake of the membranes (coloured online)

\section{CONCLUSIONS}

A series of hybrid proton conductive polyacrylate/ silica membranes with different inorganic contents were prepared by UV-initiated radical polymerization in combination with in situ sol-gel process. The proton conductivity of the synthesized membranes is in a range of $1.2-2.9 \mathrm{mS} / \mathrm{cm}$ and water uptake reaches $18-24 \mathrm{wt} . \%$. The resultant hybrid membranes had a good thermal stability as well as a relatively high oxidative stability upon treatment with Fenton's reagent at room temperature for 14 days. It can be concluded that the proposed method provides the preparation of the membranes with good characteristics for the use in fuel cells.

Received 17 September 2020

Accepted 22 September 2020

\section{References}

1. [https://www.cleantech.com/report/2019-global cleantech-100-report/].

2. E. Ogungbemi, O. Ijaodola, F. N. Khatib, et al., Energy, 172, 155 (2019).

3. T. Wilberforce, Z. El-hassan, F. N. Khatib, et al., Int. J. Hydrogen Energy, 42, 25695 (2017).

4. A. Olabi, Energy, 108, 1 (2016).

5. C. Laberty-Robert, K. Valle, F. Pereira, et al., Chem. Soc. Rev., 40, 961 (2011).
6. M. Aparicio, J. Mosa, M. Etienne, et al., J. Power Sources, 145, 231 (2005).

7. C. Wu, Y. Wu, T. Xu, et al., J. Appl. Polym. Sci., 107, 1865 (2008).

8. S. Li, M. Liu, Electrochim. Acta, 48, 4271 (2003).

9. J. Mosa, A. Duran, M. Aparicio, J. Power Sources, 297, 208 (2015).

10. A. Schechter, R. Savinell, Solid State Ion., 147, 181 (2002).

11. Sh. An, J. Liu, J. Wang, et al., Desalination, 464, 8 (2019).

12. M. Zhyhailo, O. Demchyna, Kh. Demydova, et al., Series of Chemistry, Materials Technology and their Application, 886, 58 (2018).

13. M. Zhyhailo, O. Demchyna, Kh. Demydova, et al., Chem. Chem. Technol., 13, 436 (2019).

14. M. Zhyhailo, O. Demchyna, I. Yevchuk, et al., Vopr. Khimii i Khimicheskoi Tekhnologii (Issues of Chemistry and Chemical Technology), 5, 34 (2019).

15. G. Socrates, Infrared and Raman Characteristic Group Frequencies. Tables and Charts, 3rd edn., John Wiley and Sons, Ltd (2001).

16. S. Martwiset, K. Chaisaward, S. Treepet, et al., Int. J. Hydrogen Energy, 42, 1 (2017).

17. M. Zhu, B. He, W. Shi, et al., Fuel, 89, 2299 (2010).

18. T. Kamjornsupamitra, T. Sangthumchai, et al., Int. J. Hydrogen Energy, 43, 11190 (2018).

19. K. M. Shin, J. J. Kim, K. D. Suh, J. Colloid Interface Sci., 581, 350 (2010).

20. S. Zhong, X. Cui, S. Dou, et al., J. Power Sources, 195, 3990 (2010).

21. S. Sundar, W. Jang, C. Lee, et al., J. Polym. Sci. B Polym. Phys., 43, 2370 (2005).

22. B. Fanzhe, Z. Yurong, H. Lihua, et al., J. Membr. Sci., 545, 167 (2018).

Mariia Zhyhailo, Iryna Yevchuk, Mykhaylo Yatsyshyn, Sergiy Korniy, Oksana Demchyna, Rostyslav Musiy, Rimantas Raudonis, Aleksej Žarkov, Aivaras Kareiva

\section{POLIAKRILATO / SILICIO DIOKSIDO MEMBRANŲ SINTEZĖ KURO ELEMENTỤ TAIKYMAMS UV POLIMERIZACIJOS BÜDU}

Santrauka

Straipsnyje aprašoma laidžių protonams poliakrilato membranų, kurių pagrindas yra akrilnitrilas, natrio 4 vinilbenzensulfonatas, akrilo rūgštis, etilenglikolio dimetakrilatas ir hibridinès poliakrilato / silicio dioksido membranos, kūrimas. Poliakrilato membranos buvo susintetintos naudojant UV inicijuotą kopolimerizaciją. Poliakrilato / silicio dioksido membranų sintezei polimerizuojančiame mišinyje buvo taikoma 3-metakriloksipropiltrimetoksisilano pagrindu pagaminta zolių-gelių sistema. 